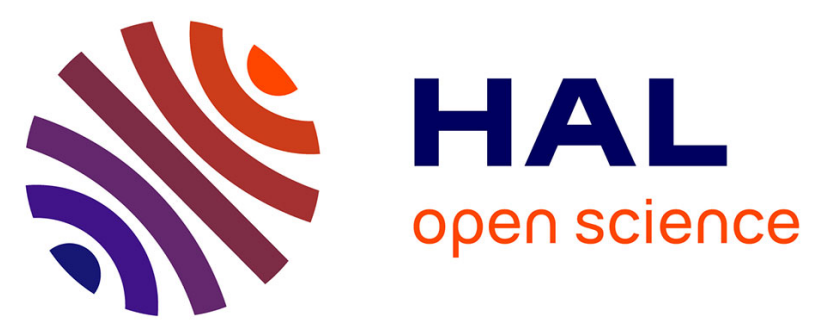

\title{
Clonal plant production from self- and cross-pollinated seed families of Pinus sylvestris (L.) through somatic embryogenesis
}

Marie-Anne Lelu-Walter, Michèle Bernier-Cardou, Krystyna Klimaszewska

\section{- To cite this version:}

Marie-Anne Lelu-Walter, Michèle Bernier-Cardou, Krystyna Klimaszewska. Clonal plant production from self- and cross-pollinated seed families of Pinus sylvestris (L.) through somatic embryogenesis. Plant Cell, Tissue and Organ Culture, 2008, 92 (1), pp.31-45. 10.1007/s11240-007-9300-x . hal02657682

\section{HAL Id: hal-02657682 \\ https://hal.inrae.fr/hal-02657682}

Submitted on 30 May 2020

HAL is a multi-disciplinary open access archive for the deposit and dissemination of scientific research documents, whether they are published or not. The documents may come from teaching and research institutions in France or abroad, or from public or private research centers.
L'archive ouverte pluridisciplinaire HAL, est destinée au dépôt et à la diffusion de documents scientifiques de niveau recherche, publiés ou non, émanant des établissements d'enseignement et de recherche français ou étrangers, des laboratoires publics ou privés. 
Version détinitive du manuscrit publié dans / Final version of the manuscript published

in : Plant Cell Tissue and Organ Culture. 2008, 92 (1) : 31-45

2 Clonal plant production from self- and cross-pollinated seed families

3 of Pinus sylvestris (L.) through somatic embryogenesis

4

5 Marie-Anne Lelu-Walter ${ }^{1}$, Michèle Bernier-Cardou ${ }^{2}$, Krystyna Klimaszewska ${ }^{2}$

9 INRA, Unité Amélioration, Génétique et Physiologie Forestières, Centre Recherches d'Orléans, 10 BP 20619 Ardon F-45166 Olivet Cedex, France

$11{ }^{2}$ Natural Resources Canada, Canadian Forest Service, Laurentian Forestry Centre, $1055 \mathrm{du}$

12 P.E.P.S., P.O. Box 10380, Stn. Sainte-Foy, Quebec, Quebec G1V 4C7, Canada

$14 \quad$ Leluwa@orleans.inra.fr

15 Tel: + 33-2-38 417839

16 Fax: + 33-2-38 414809 
1 Keywords Maturation Scots pine Somatic embryos Storage proteins

2

3 Abstract Several factors affecting somatic embryogenesis (SE) in Pinus sylvestris from self-

4 and cross-pollinated seed families were studied with the aim of producing large quantities of

5 clonal plants. SE initiation from zygotic embryos was improved on a medium with lower than

6 standard concentrations of 2,4-dichlorophenoxyacetic acid (2.2 vs $9.5 \mu \mathrm{M})$ and 6-benzyladenine

7 (2.2 vs $4.5 \mu \mathrm{M})$. On this medium, initiation rates of four controlled crosses, including one self-

8 cross, varied from $3 \%$ to $25 \%$. Among the maturation factors tested, the concentration of abscisic

9 acid (ABA 80, $120 \mu \mathrm{M})$ had no significant effect on the production of mature somatic embryos

10 when the medium contained $0.1 \mathrm{M}$ sucrose. When sucrose concentration was $0.2 \mathrm{M}$, however, 1.4

11 times more mature somatic embryos were produced on medium with $80 \mu \mathrm{M}$ compared with 120

$12 \mu \mathrm{M}$ ABA. Under our best maturation conditions, mature somatic embryos accumulated amounts

13 of storage proteins that were similar to the amounts in mature zygotic embryos. Activated

14 charcoal exerted a beneficial effect on mature somatic embryo production of 24-week-old

15 cultures; there was no evidence of such an effect in 8-week-old cultures. Thirty seven

16 embryogenic lines from a self-cross and an out-cross were chosen for clonal plant production.

17 Highly embryogenic lines produced mature somatic embryos that were more likely to convert to

18 plants than those from less embryogenic lines. After 4 months of growth in a shade house,

19 plantlet survival rates exceeded $70 \%$ for 31 lines out of 35 . This report describes an improved

20 method for accelerated production of large quantities of Scots pine for clonal tests.

22 Abbreviations ABA, abscisic acid; AC, activated charcoal; BA, benzyladenine; 2,4-D, 2,423 dichlorophenoxyacetic acid; DMSO, dimethylsulphoxide; EM, embryonal mass; f.m., fresh 24 mass; PGR, plant growth regulator 


\section{Introduction}

3 Somatic embryogenesis (SE) in conifers has become a powerful biotechnological tool for clonal

4 plant production. As such, it has the potential of being applied in tree improvement programs and

5 in research involving screening for disease resistance and other desirable traits because it may deliver any number of clonal individuals for either clone selection or pathogen and pest challenging tests.

8 Pinus sylvestris (Scots pine) has a wide natural distribution throughout much of Eurasia, and adaptation capabilities to diverse environments (Boratynski 1991). In France, gains in the genetic quality of Scots pine plantations are expected from improved breeding populations created from natural populations. Scots pine plantations at Haguenau, in eastern France, are appreciated for their superior height and diameter growth (Quencez and Bastien, 2000). In this context, our study was undertaken to improve existing protocols of Pinus sylvestris SE and apply these

14 enhancements to embryogenic lines derived from immature zygotic embryos of the natural 15 population of Haguenau for clonal plant production.

The first reports of SE in Scots pine focused mainly on initiation from immature seed, and investigated the responses of excised zygotic embryos at several developmental stages on various culture media (Keinonen-Mettälä et al. 1996; Lelu et al. 1999; Häggman et al. 1999). While regeneration of small numbers of somatic seedlings and young trees was achieved in those 20 studies, efforts were not aimed specifically at developing somatic embryo maturation protocols 21 for the efficient production of large numbers of clonal plants. Elsewhere, a diallel cross among 22 seven parent trees was conducted to evaluate the effect of parent genotype on SE (Niskanen et al. 23 2004). There was a strong maternal effect on initiation of SE that was mostly independent of the 24 paternal effect, a conclusion also reached in another study on Pinus taeda (MacKay et al. 2006).

25 In the present work, we focused on SE initiation from four controlled crosses, including one 26 self cross, among three trees that had previously been tested for their response to initiation (Lelu 27 et al. 1999). In other experiments, the effect of several factors on the maturation of somatic 28 embryos was investigated. Those were culture age, abscisic acid concentration of the medium, its 29 sucrose concentration and coating of the cells with activated charcoal (AC). The storage protein 30 contents of cotyledonary somatic embryos of three distinct phenotypes, matured under the best of 31 tested conditions, was measured and compared with that of zygotic embryos. Accumulation of 
1 storage proteins could be used to assess the quality of somatic embryos and to determine optimal

2 harvest time. Subsequently, the improved protocols were used to assess production of plants

3 from embryogenic lines of an out-cross and a self-cross. 
Materials and methods

3 Plant materials

5 Pinus sylvestris (L.) trees 818 (A), $785(\mathrm{~B})$ and $666(\mathrm{C})$ originated from eastern France

6 (Haguenau). Open pollinated seeds of these trees were tested previously for their ability to

7 initiate SE (Lelu et al. 1999). Tree A appeared the most responsive to initiation of SE with an

8 initiation rate of $22 \%$ among seed explants, whereas trees $\mathrm{B}$ and $\mathrm{C}$ had initiation rates of $9 \%$ and

$90 \%$, respectively.

10 For the present study, the following controlled crosses were performed at INRA, Orléans, 11 France, in 1999 and 2003: A x B, C x A, A x C and one self-cross, A x A. Immature cones were 12 collected from mother trees twice: on 19 June 2000 and on 21 June 2004.

14 Initiation of SE and proliferation of embryonal mass (EM) (Experiments 1)

16 Prior to seed extraction, each cone was submerged in $95 \%$ (v/v) ethanol for $10 \mathrm{~min}$, briefly dried 17 in the laminar flow unit, and cut longitudinally into 2 pieces. Subsequently, scales with immature 18 seeds were detached from the cone; seeds were picked with sterile forceps and placed on a sterile surface. During this procedure, the immature seeds were not disinfected; yet the contamination 20 rate of the cultures was less than 0.1\%. Based on previously published results (Lelu et al. 1999), 21 seeds were extracted when the zygotic embryos were at the cleavage polyembryony stage. At 22 this early developmental stage, megagametophytes that contained zygotic embryos were 23 carefully removed from the seed coat, nucellus and megaspore wall, and cultured intact on 24 initiation medium. Explants were cultured in $90 \times 20 \mathrm{~mm}$ Petri dishes, each of which contained 25 approximately $30 \mathrm{ml}$ of a semi-solid medium (Litvay et al. 1985) modified by reducing the 26 concentration of macro elements by $50 \%$ (except iron and EDTA) and adding $1 \mathrm{gl}^{-1}$ casein $^{2}$ 27 hydrolysate (enzymatic, SIGMA, CH), $0.5 \mathrm{gl}^{-1}$ L-glutamine (SIGMA), $30 \mathrm{gl}^{-1}$ sucrose, 2.428 dichlorophenoxyacetic acid (2,4-D) at either 9 or $2.2 \mu \mathrm{M}, 6$-benzyladenine (BA) at either 4.4 or $292.3 \mu \mathrm{M}$, and $4 \mathrm{gl}^{-1}$ gellan gum (Phytagel ${ }^{\mathrm{TM}}$, SIGMA). The medium with the higher concentrations 30 of 2,4-D and BA was designated as mLV-S (for standard concentration of plant growth 
1 regulators, PGRs), and that with lower concentrations of the two compounds as mLV-L (for low

2 PGRs). The medium without PGRs is subsequently referred to as the mLV medium.

3 The $\mathrm{pH}$ of each medium was adjusted to 5.8 after the addition of gellan gum. An appropriate

4 aliquot of filter-sterilized stock solution of glutamine (also pH-adjusted to 5.8) was added to the

5 medium after autoclaving. The explants, usually 10 per Petri dish, were cultured for up to 10

6 weeks in darkness at approximately $25^{\circ} \mathrm{C}$ and were not subcultured during the whole period.

7 They were considered as having initiated SE if EM could be identified under the stereoscope.

8 After 10 weeks, EM that showed continuous growth and produced amounts of fresh mass (f. m.)

9 sufficient for subculture was considered to have "proliferated".

10 Some explants from crosses A x A and C x A initiated minute amounts of EM, but after 3 to 4 11 weeks, the tissue stopped growing. To "rescue" these lines and promote growth, the EM was 12 suspended in a small volume of liquid medium and cultured on a filter paper disk (see below).

14 Experiment 1a: effect of PGR concentration

16 The effect of PGR concentration of the medium (low or standard) on the rate of EM initiation 17 was assessed from explants of the A x B cross. The experiment was run in two blocks of 16 and 1821 Petri dishes, respectively. The first block contained 8 Petri dishes for each medium, and the 19 second, 11 Petri dishes with the standard PGR concentration medium, and 10 with the mLV-L 20 medium. Petri dishes with initiated SE were used to assess the effect of PGRs on the rate of EM 21 proliferation: in the first block, there were 3 such Petri dishes with mLV-S medium and 8 with $22 \mathrm{mLV}$-L medium, and in the second, there were 10 Petri dishes from each PGR level.

24 Experiment 1b: effect of crosses

26 Rates of SE initiation by explants from four crosses ( C x A, A x A, A x B and A x C) were 27 compared on mLV-L medium. Explants from each cross were distributed in 11 to 17 Petri dishes 28 for a total of 57 Petri dishes. Rates of EM proliferation, given initiation, could be assessed from 4 29 to 13 Petri dishes per cross. 
2 First and subsequent subcultures of EM

4 The age of the embryogenic culture was set to 0 the day of the first subculture. Subsequently, the 5 embryonal mass was subcultured every two weeks onto fresh mLV-Lmedium, except that the 6 sucrose concentration was reduced to $20 \mathrm{gl}^{-1}$. Approximately $300 \mathrm{mg}$ f.m. of proliferating EM 7 was collected and suspended in 4 to $5 \mathrm{ml}$ of liquid mLV-L medium, vigorously shaken to break 8 up the tissue pieces into a fine suspension, and poured onto a filter paper (Whatman \# 2, 9 diameter $7 \mathrm{~cm}$ ) in a Büchner funnel. Low-pressure pulse was applied to drain the liquid, and the 10 filter paper with attached cells was placed on the surface of fresh, semi-solid mLV-L medium 11 and cultured in darkness at approximately $25^{\circ} \mathrm{C}$ for 2 weeks. This procedure yielded 2 to $10 \mathrm{~g}$ of 12 EM per filter paper disc depending on the line. All initiated embryogenic lines from crosses $13 \mathrm{~A} \times \mathrm{A}$ and $\mathrm{C} \times \mathrm{A}$ stopped growing after reaching approximately 20 to $50 \mathrm{mg}$ f.m. To promote 14 growth of these lines, an explant with initiated EM was placed in a sterile Eppendorf tube with 150.5 to $1 \mathrm{ml}$ of liquid mLV-L medium, shaken to break up the tissue clumps and poured onto a 16 filter paper disc (Whatman \# 2, diameter $7 \mathrm{~cm}$ ) in a Büchner funnel. The filter paper with 17 attached cells was placed on the surface of fresh, semi-solid mLV-L medium and cultured.

Cryopreservation protocol

21 The cryopreservation protocol used in this study has been previously published for P. monticola 22 (Percy et al. 2000) and routinely applied since then to other conifer species (Lelu-Walter et al. 23 2006, K. Klimaszewska and M.-A. Lelu-Walter, unpublished). Briefly, 3 g f.m. embryogenic 24 tissue cultured on filter paper for $7 \mathrm{~d}$ were suspended in $12 \mathrm{ml}$ of liquid $\mathrm{mLV}$-L medium 25 supplemented with $0.4 \mathrm{M}$ sorbitol for $18 \mathrm{~h}$. Subsequently, $3 \mathrm{ml}$ of dimethyl sulphoxide (DMSO, 26 SIGMA) was added to the suspension on ice (final DMSO concentration 7.5\%). After $1.5 \mathrm{~h}, 1 \mathrm{ml}$ 27 of suspension was transferred to a cryovial in a Nalgene ${ }^{\mathrm{TM}} \mathrm{Cryo} 1^{\circ} \mathrm{C}$ Freezing Container that was 28 placed in a freezer at $-80^{\circ} \mathrm{C}$ for $2 \mathrm{~h}$. The vials were then submerged and stored in liquid nitrogen. 29 Of 12 vials frozen per embryogenic line, two were thawed after 24 h to test culture recovery.

30 Seventeen lines, four from the A x B cross and 13 from the A x C cross, were frozen.

31 Proliferation on filter papers yielded large quantities of EM and cryopreservation could be 
1 carried out with lines as young as 2 weeks (since the first subculture). Until now, this

2 cryopreservation technique has resulted in the recovery of all tested lines. Over the years,

3 cryopreserved lines were routinely used in the experiments. Cryopreservation per se and its

4 duration (up to 3 years) had no apparent effect on the yield of somatic embryos (data not shown).

5 Experiments in which cryopreserved material was used are identified.

7 Factors influencing maturation of somatic embryos (Experiments 2)

9 A first set of maturation experiments were conducted with 7 lines initiated in 1999 (2 LS lines)

10 and in 2000 (5 MS lines). Line LS4 originated from the A x C cross, and lines LS8, MS1, MS6,

11 MS11, MS15 and MS17, from the A x B cross. The experiments were conducted between 2000

12 and 2004. They were designed to investigate the effects of various concentrations of abscisic

13 acid (ABA, racemic, SIGMA) and sucrose in the maturation medium on the production of

14 mature somatic embryos of one or several embryogenic lines sampled at one or more culture

15 ages. Quantities of EM required in any experiment were collected approximately 1 week after

16 subculture and suspended (by vigorous shaking) in liquid $\mathrm{mLV}$ medium with $0.08 \mathrm{M}$ sucrose,

17 without PGRs. Five $\mathrm{ml}$ of the suspension containing from 200 to $289 \mathrm{mg}$ f.m. of EM were then

18 poured onto a filter paper disc, as described above, and placed on mLV maturation medium

19 containing $10 \mathrm{gl}^{-1}$ of gellan gum, and ABA and sucrose in concentrations specific to each

20 experiment. The ABA stock solution was filter sterilized and added to the molten medium after

21 autoclaving. The medium was dispensed into $90 \times 20-\mathrm{mm}$ Petri dishes at approximately $40 \mathrm{ml}$

22 per dish. Cultures were placed under a 16-h photoperiod, dim light $\left(5 \mu \mathrm{mol} \mathrm{m}{ }^{-2} \mathrm{~s}^{-1}\right)$ at

23 approximately $24 / 21^{\circ} \mathrm{C}$ day/night temperature for 12 weeks, and were not subcultured during the

24 course of the experiments. Productivity was measured as the number of morphologically normal

25 mature somatic embryos per Petri dish produced over the 12-week period. Features specific to

26 each experiment and exceptions to the general conditions above follow.

28 Experiment 2a: effect of ABA and sucrose concentrations

30 In the first of the maturation experiments, mean somatic embryo production of line MS6 on

31 maturation media containing either of four combinations of ABA $(80$ or $120 \mu \mathrm{M})$ and sucrose 
$1(0.1 \mathrm{M}$ or $0.2 \mathrm{M})$ concentrations was compared. There were 3 to 6 Petri dishes per ABA and 2 sucrose concentrations, for a total of 17.

3

4 Experiment $2 \mathrm{~b}$ : effect of ABA concentration combined with $0.1 \mathrm{M}$ sucrose 5

6 The effect of the two ABA concentrations of the maturation medium, 80 and $120 \mu \mathrm{M}$, on 7 somatic embryo production was also assessed for embryogenic tissue of lines MS1, MS6, MS11 8 and MS15 from the A x B cross. The embryogenic cultures were about 4 weeks old, and the 9 sucrose concentration of the maturation medium was $0.1 \mathrm{M}$. There were 2 or 3 Petri dishes per 10 line, per ABA concentration for a total of 22.

12 Experiment 2c: effect of ABA concentration combined with $0.2 \mathrm{M}$ sucrose 13

14 The same ABA concentrations of the maturation medium, 80 and $120 \mu \mathrm{M}$, were tested with 15 embryogenic tissue of line LS4 from the A x C cross, and lines LS8, MS6, MS15 and MS17 16 from cross A x B. Culture ages of the embryogenic tissue, which was retrieved from 17 cryopreservation, varied from 6 to 14 weeks. The maturation medium contained $0.2 \mathrm{M}$ sucrose. 18 The number of Petri dishes per line, per ABA level varied from 3 to 10 for a total of 108 Petri 19 dishes.

21 Experiment 2d: effect of activated charcoal (AC)

23 In another experiment, half the EM was suspended in liquid mLV medium containing AC

24 (Merck, at $\left.10 \mathrm{gl}^{-1}\right)$. The cells were then cultured on maturation medium containing ABA (80 $25 \mu \mathrm{M})$, sucrose $(0.2 \mathrm{M})$ and gellan gum $\left(10 \mathrm{gl}^{-1}\right)$, as previously described. When the liquid 26 suspension medium contained AC, both cells and AC particles coating the cell aggregates were 27 collected on the filter paper. The AC effect was tested on three lines: LS4 from the A x C cross, 28 and MS6 and LS8 from cross A x B. Cultures were either 8 or 24 weeks old at the onset of this 29 maturation experiment and were retrieved from cryopreservation. There were 4 to 10 Petri dishes 30 per line, per $\mathrm{AC}$ level $\left(0\right.$ or $\left.10 \mathrm{gl}^{-1}\right)$, per culture age, for a total 86 Petri dishes. 
1 Storage protein extraction and quantification in zygotic and somatic embryos

3 Cotyledonary somatic embryos of line MS6 (A x B cross) that developed on medium containing

$40.2 \mathrm{M}$ sucrose, $80 \mu \mathrm{M} \mathrm{ABA}$ and $10 \mathrm{gl}^{-1}$ gellan gum were collected for storage protein

5 quantification. After 8 weeks of maturation, somatic embryos reached the cotyledonary stage and appeared totally white. After 10 to 12 weeks of maturation there were distinct differences among

7 the cotyledonary somatic embryos with respect to their color. Some had yellow cotyledons and

8 white hypocotyl, and others, green cotyledons with yellowish hypocotyl. To determine if the 9 different phenotypes were associated with varying levels of storage reserves, total proteins were 10 extracted and quantified. Their quantities were compared with those of mature zygotic embryos 11 harvested at the end of November. Methods of total protein extraction, electrophoresis and 12 quantification in zygotic and somatic embryos were identical to those described in Klimaszewska 13 et al. (2004). Briefly, total proteins were extracted from $15 \mathrm{mg}$ f.m. frozen embryos in $500 \mu \mathrm{l}$ 14 Tris- $\mathrm{HCl}$ buffer ( $\mathrm{pH} 6.8)$ containing $2 \% \mathrm{SDS}(\mathrm{w} / \mathrm{v})$ and $28 \%(\mathrm{v} / \mathrm{v})$ glycerol, and then heated to $1595^{\circ} \mathrm{C}$ for $15 \mathrm{~min}$. To reduce the samples, $\beta$-Mercaptoethanol was added to the extraction buffer at $165 \%(\mathrm{v} / \mathrm{v})$ prior to heating. The extracts were then centrifuged at $15000 \mathrm{~g}$ for 5-10 min and the 17 supernatants were collected. Protein concentration in each sample extract was determined using 18 the Bradford protein assay (Bio-Rad Protein Assay kit; Bio-Rad, Hercules, CA). Sodium dodecyl 19 sulphate-polyacrylamide gel electrophoresis (SDS-PAGE) was carried out following standard 20 protocols. After SDS-PAGE the gels were stained with Coomassie blue R-250. Protein bands 21 were quantified with the SYNGENE Bio Imaging System (Frederick, MD) in two gels.

23 Plant production from lines of crosses A x A and A x B (Experiments 3)

25 Experiment 3a: maturation of somatic embryos

27 Based on the previous experiments, mLV medium containing $0.2 \mathrm{M}$ sucrose, $80 \mu \mathrm{M} \mathrm{ABA}$ and 10 $28 \mathrm{gl}^{-1}$ gellan gum was selected to promote somatic embryo development in 35 lines (4 lines from 29 A x A and 31 lines from A x B). Culture age was about 19 weeks, and there were 3 to 8 Petri 30 dishes per line for a total of 189 Petri dishes. Productivity was assessed as in Experiments 2. 
1 Experiment 3b: conversion of somatic embryos to plants

3 Mature, morphologically normal, white somatic embryos from 37 lines (5 lines from A x A and

432 lines from A x B), including those tested in Experiment 3a, were picked from Petri dishes

5 after 12 weeks of maturation and placed horizontally, all in the same orientation, on the surface

6 of mLV medium without PGRs, with $30 \mathrm{gl}^{-1}$ sucrose and $4 \mathrm{gl}^{-1}$ gellan gum to promote

7 germination and conversion to plants. In this germination phase, there were 7 to 32 somatic

8 embryos per Petri dish ( $90 \times 20 \mathrm{~mm}$ ), usually 15, 20 or 25, and a total of 158 Petri dishes, each

9 containing $30 \mathrm{ml}$ of medium. The Petri dishes were tilted vertically at an angle of approximately

$1035^{\circ}$ to $40^{\circ}$ and placed in darkness for 10 to 14 days at day/night temperatures of $24 / 21^{\circ} \mathrm{C}$ to

11 promote hypocotyl elongation and reduce anthocyanin accumulation. Somatic embryos were

12 then exposed to a $16-\mathrm{h}$ photoperiod $\left(10 \mu \mathrm{mol} \mathrm{m}^{-2} \mathrm{~s}^{-1}\right)$ at $24 / 21^{\circ} \mathrm{C}$ day/night temperatures. The

13 plantlets were subcultured once onto fresh medium of the same composition after 6 to 7 weeks.

14 The number of somatic embryos that germinated and converted to a plant after 16 weeks of 15 germination was noted for each Petri dish.

17 Experiment 3c: acclimatization of somatic plants

19 For further plant production, 30 to 40 somatic plantlets from 35 lines (4 lines from A x A and 31

20 lines from A x B) were transferred from Petri dishes to a potting mix composed of peat moss

21 (75\%), vermiculite (25\%) and slow release fertilizer osmocote $\left(750 \mathrm{gm}^{-3}\right)$ in trays. The trays

22 were placed directly in a shade house at INRA, Orléans, France, in mid May 2005. During the

23 first 2 to 3 weeks, a misted plastic sheet covered the plantlets to maintain high humidity. It was

24 then lifted progressively. Plants were watered as needed. After 1 month, the somatic plants were

25 treated as seedlings of a similar age. The survival of each plant was assessed 4 months after

26 transfer to the shade house. In March 2006, 10 months after acclimatization, plants were selected 27 and transferred to soil in the nursery.

29 Statistical Analysis

31 Most statistical models were of the generalized linear type (Agresti 2002, Chapters 4-6; Mize et 
1 al. 1999). When the response variable was a number of "successes" (initiation, proliferation, 2 conversion to plantlet, or plant survival after 4 months) out of a number of "trials" (explants, or 3 plantlets), it was assumed to follow a binomial distribution. When it was a count, the number of 4 somatic embryos produced from EM in a Petri dish, it was assumed to follow a Poisson 5 distribution. Unless otherwise stated, models included an over-dispersion parameter, which accounted for variation among Petri dishes within medium, cross or line. It was estimated by Pearson's method. Means and their 95\% confidence limits were computed on a transformed 8 scale, the logit for binomial rates, and natural logarithm for Poisson counts, and backtransformed for presentation in the tables or in the text. In the latter, pairs of numbers in parentheses that follow a mean rate, a mean count or a ratio of mean counts are its $95 \%$ confidence limits (C.L.). Models for counts included initial fresh mass (f.m.) of EM per Petri dish as an offset variable so that the mean number of somatic embryos is expressed on the basis of $1 \mathrm{~g}$ f.m. of EM. Equality between any two mean binomial rates was assessed by testing the 14 equivalent null hypothesis that the difference between their logits was zero. A priori contrasts were the preferred method of comparison among means. All statistical tests were performed at 16 the $\alpha=0.05$ level. Observed p-values are denoted by lower case $p$, and degrees of freedom 17 associated with F or chi-squared $\left(\chi^{2}\right)$ statistics, by d.f. Analyses were performed with the 18 GENMOD procedure of SAS software (Version 9.1, SAS Institute Inc., NC; see also Littell et al. 19 2002, Chapter 10).

20 Two specific models are detailed below as examples: one for the SE initiation rate of 21 Experiment 1b, and the other for the somatic embryo count of Experiment 2d. Specific models 22 can be inferred from the information provided in the tables. Consider the logit model for the rate 23 of SE initiation among explants in Experiment 1b. Let $\mathrm{P}_{\mathrm{Ii}}$ denote the expected rate of initiation in 24 Petri dish $j\left(j=1, \ldots, n_{i}\right.$ where $n_{i}$ is the number of Petri dishes from cross $i, i=1,2,3,4$ for 25 crosses $\mathrm{A} \times \mathrm{C}, \mathrm{A} \times \mathrm{B}, \mathrm{C} \times \mathrm{A}$ and $\mathrm{A} \times \mathrm{A}$, respectively) containing $\mathrm{m}_{\mathrm{ij}}$ explants from cross $\mathrm{i}$. It was 26 assumed that $\mathrm{r}_{\mathrm{ij}}$, the observed number of explants that initiated SE in this Petri dish, followed a 27 binomial distribution, and that the logit of $\mathrm{P}_{\mathrm{Ii}}$ depended linearly on four parameters:

$$
\log \operatorname{it}\left(\mathrm{P}_{\mathrm{Ii}}\right)=\log \left(\frac{\mathrm{P}_{\mathrm{Ii}}}{100-\mathrm{P}_{\mathrm{Ii}}}\right)=\mu+\tau_{\mathrm{i}}
$$

29 where $\mu$ is a reference parameter corresponding to the self cross A x A (i=4), $\tau_{i}$ is the difference 30 between the $\operatorname{logit}\left(\mathrm{P}_{\mathrm{Ii}}\right)$ for cross $\mathrm{i}(\mathrm{i}=1,2,3)$ and that for cross $\mathrm{A} \times \mathrm{A}$, and $\tau_{4}=0$. A priori 
1 contrasts between the initiation rates of the four crosses were also performed on that scale. For example, equality of $\mathrm{P}_{\mathrm{I} 4}$ for the self and $\mathrm{P}_{\mathrm{I} 3}$ for the $\mathrm{C} \times \mathrm{A}$ cross was tested as $\mathrm{H}_{0}: \tau_{3}=\tau_{4}$ vs $\mathrm{H}_{1}: \tau_{3}$

$3 \neq \tau_{4}$, which is equivalent.

4 The analysis of EM proliferation rates in Experiment 1b was based on a model much like [1] except for the definition of $\mathrm{P}_{\mathrm{Ii}}$ which became the expected proliferation rates for cross $\mathrm{i}, \mathrm{P}_{\mathrm{Pi}}$, given initiation of SE. In Experiment 1a, the initiation and proliferation rates were also analyzed with a model like [1], but the $\tau_{\mathrm{i}}$ 's were the effects of the two PGR levels, low and standard, $\mathrm{i}=1$,

82 , with $\tau_{2}=0$. The rate of conversion to plant in Experiment $3 \mathrm{~b}$ was also based on models similar to [1] with $\tau_{i}$ 's $(i=1, \ldots, 37)$ representing line effects. A contrast between the $\tau_{i}$ 's was constructed to compare lines from the self- and out-cross. In Experiment 3c, the overdispersion parameter of the model for the survival rate after 4 months was set to 1 since plantlets were treated individually.

13 Experiment $2 \mathrm{~d}$ provides an example with counts of somatic embryos. It involved three factors:

$14 \mathrm{AC}(\mathrm{i}=1$ for presence, $\mathrm{i}=2$ for absence), line $(\mathrm{j}=1,2,3$ for lines LS4, LS8 and MS6, 15 respectively) and culture age ( $\mathrm{k}=1$ for 8 weeks, and $\mathrm{k}=2$ for 24 weeks). It was assumed that $y_{\mathrm{ijk}}$, the number of somatic embryos counted in the $1^{\text {th }}$ Petri dish with the $i^{\text {th }}$ AC level, $j^{\text {th }}$ line and $\mathrm{k}^{\text {th }}$ culture age $\left(1=1, \ldots, \mathrm{n}_{\mathrm{ijk}}\right.$, and $\mathrm{n}_{\mathrm{ijk}}$ is the number of Petri dishes per combination of AC level, line and culture age) followed a Poisson distribution with mean $\mu_{\mathrm{ijk}}$. The model was:

$$
\log \left(\mu_{\mathrm{ijk}} \mid \mathrm{x}_{\mathrm{ijk} \mathrm{k}}\right)=\mu+\tau_{\mathrm{i}}+\lambda_{\mathrm{j}}+(\tau \lambda)_{\mathrm{ij}}+\alpha_{\mathrm{k}}+(\tau \alpha)_{\mathrm{ik}}+(\lambda \alpha)_{\mathrm{jk}}+(\tau \lambda \alpha)_{\mathrm{ijk}}
$$

20 where $\mu_{\mathrm{ijk}}$ is the expected embryo count $\mathrm{g}^{-1}$ f.m. in the $\mathrm{l}^{\text {th }}$ Petri dish at levels $\mathrm{i}, \mathrm{j}$ and $\mathrm{k}$ of the $\mathrm{AC}$, 21 line and age factors, respectively, $\mathrm{x}_{\mathrm{ijkl}}$ is the embryogenic mass deposited on that Petri dish, $\mu$ is a 22 reference parameter corresponding to absence of AC $(i=2)$, line MS6 $(j=3)$ and 24-week-old 23 cultures $(\mathrm{k}=2), \tau_{\mathrm{i}}$ is the effect of level $\mathrm{i}$ of $\mathrm{AC}\left(\tau_{2}=0\right), \lambda_{\mathrm{j}}$ is the effect of line $\mathrm{j}\left(\lambda_{3}=0\right), \alpha_{\mathrm{k}}$ is the 24 effect of culture age $\mathrm{k}\left(\alpha_{2}=0\right)$, and $(\tau \lambda)_{\mathrm{ij}},(\tau \alpha)_{\mathrm{ik}},(\lambda \alpha)_{\mathrm{jk}}$, and $(\tau \lambda \alpha)_{\mathrm{ijk}}$ are interaction effects 25 between $\mathrm{AC}$ levels, lines and culture ages. The $\mu_{\mathrm{ijk}}$ 's at various combinations of the factor levels 26 were compared on the logarithmic scale through a priori contrasts between the $\tau_{i}$ 's, the $\lambda_{j}$ 's, the $27 \alpha_{\mathrm{k}}$ 's or the interaction parameters of model [2]. Similar, but simpler models were constructed to 28 analyze counts of somatic embryos in Experiments 2a, 2b, 2c and $3 a$. 


\section{Results}

3 SE initiation and EM proliferation (Experiments 1)

5 SE initiation did not guarantee continued proliferation of EM. In the self cross A $x$ A and the outcross $\mathrm{C}$ x A, the initiated EM did not proliferate unless cultured on a filter paper (see

7 Materials and Methods section). Proliferation of some lines from these crosses was the result of

8 this specific culture technique (Experiment 1b). For the A x A cross, six lines were rescued out

9 of 13 initiated, and for the C x A cross, five lines out of 17 initiated. Generally, SE initiation

10 required 5 to 7 weeks, after which the tissue was subcultured and proliferated further.

12 Experiment 1a: PGR concentration

14 In Experiment 1a, explants were more likely to initiate SE on mLV-L medium than on mLV-S 15 medium $(\mathrm{p}=0.0002$, Table 1). However, EM proliferation rates did not appear to differ between 16 the two media $(\mathrm{p}=0.25)$.

18 Experiment 1b: Initiation and proliferation rates of four controlled crosses

20 Initiation rates differed among the four crosses tested in Experiment $1 \mathrm{~b}(\mathrm{p} \leq 0.0001$, Table 2). On 21 average, they were higher for the out-cross of mother tree A with father trees B and C than for 22 the self cross A x A ( $\leq \leq 0.0001)$. They did not differ significantly between the two out-crosses 23 of mother tree $A(p=0.47)$. The initiation rate of explants from these two out-crosses averaged $24 \mathrm{P}_{\mathrm{I}, \mathrm{AxB} \text { or } \mathrm{AxC}}=22 \%$ (C.L.: 17\%, 29\%). There was no indication that initiation rates differed 25 between the out-cross of father tree A with mother tree $\mathrm{C}$ and the self-cross $(\mathrm{p}=0.35)$.

26 Given initiation, proliferation rates of EM differed somewhat among crosses $(\mathrm{p}=0.03$, Table 27 2). The mean proliferation rates of the self cross $A x A$ and the out-cross $C \times A$ did not differ 28 significantly, nor did those of the two out-crosses of mother tree A with father trees B and C 29 which averaged $\mathrm{P}_{\mathrm{P}, \mathrm{AxB} \text { or } \mathrm{AxC}}=89 \%$ (C.L.: 77\%, 95\%), but the proliferation rate of the self-cross 30 was significantly lower than that of the two out-crosses of mother tree A. 
2 Factors influencing maturation of somatic embryos (Experiments 2)

4 Experiment 2a: effect of ABA and sucrose concentrations

There was no indication that either ABA or sucrose concentrations or their interaction had any effect on somatic embryo production of line MS6 $(p=0.81,0.22$ and 0.57 for the three effects, 8 respectively).

Experiments $2 \mathrm{~b}$ and $2 \mathrm{c}$ : effect of $\mathrm{ABA}$ concentration combined with either $0.1 \mathrm{M}$ or $0.2 \mathrm{M}$ sucrose

In Experiment 2b, where the sucrose concentration of the maturation medium was $0.1 \mathrm{M}$, the effect of the ABA concentration was tested with four embryogenic lines from the highly

14 productive A x B cross. There was no indication that average somatic embryo production differed between media with 80 and $120 \mu \mathrm{M}$ of $\mathrm{ABA}(\mathrm{p}=0.68)$, nor that the effect of $\mathrm{ABA}$ concentration differed among the lines tested ( $p=0.46$ for the ABA $x$ Lines interaction).

17 Somatic embryo production varied significantly among lines from an average of $29 \mathrm{~g}^{-1} \mathrm{f} . \mathrm{m}$. of 18 EM for line MS11 to 473 for line MS6 ( $p=0.0005$ for the main effect of lines). Productivity of 19 line MS6 was 7.2 times (C.L.: 3.2, 16.0) as abundant as that of the three other lines, on average, 20 but it did not differ among the latter three lines.

21 Experiment $2 \mathrm{c}$ was similar to Experiment $2 \mathrm{~b}$ except that the maturation medium contained $\mathrm{a}$ 22 higher sucrose concentration, and most lines differed (Table 3). Somatic embryo production was 231.4 times (C.L.: 1.1, 1.9) more abundant when the medium contained $80 \mu \mathrm{M}$ ABA than when it 24 contained $120 \mu \mathrm{M}(\mathrm{p}=0.014$ for the main effect of $\mathrm{ABA})$. There was no indication that this 25 ABA effect varied among lines ( $\mathrm{p}=0.19$ for the ABA $x$ Lines interaction), but average 26 production varied considerably among lines ( $\mathrm{p} \leq 0.0001)$ : from 57 somatic embryos $\mathrm{g}^{-1}$ f.m. for 27 line MS17 to 441 for line LS4. In particular, line LS4 from the A x C cross produced 2.6 times 28 (C.L.: 1.4, 1.6) more somatic embryos than lines from the A x B cross $(\mathrm{p} \leq 0.0001)$, on average. 29 The latter lines also differed in their productivity; one of them, MS6, produced almost as many 30 somatic embryos as the A x C line, LS4. 
2 Experiment 2d: effect of $\mathrm{AC}$

4 Results from Experiment 2d suggested that the effect of $\mathrm{AC}$ on somatic embryo production 5 depended on culture age at the start of maturation ( $\mathrm{p} \leq 0.0001$ for the AC $\mathrm{x}$ Age interaction, 6 Table 4), as well as on the embryogenic line ( $p=0.006$ for the AC $x$ Lines interaction). There 7 was no indication that the effect of the $\mathrm{AC} \mathrm{x}$ Age interaction varied among lines, however $(\mathrm{p}=$ 80.18 for the $\mathrm{AC} x$ Age $\mathrm{x}$ Line interaction), or equivalently, that the effect of the interaction between $\mathrm{AC}$ and the lines changed with culture age. Culture of EM in the presence of AC 10 enhanced average somatic embryo production of line MS6 about 2-fold (the ratio of the two 11 mean counts is $2.08, p \leq 0.0001)$ and that of line LS4 by a factor of $1.4(p=0.02)$, but had no 12 apparent effect on the yield of line LS8 $(p=0.39)$. Average somatic embryo production from 813 week-old cultures did not seem affected by $\mathrm{AC}(\mathrm{p}=0.36)$, whereas production increased 2.10-

14 fold when $\mathrm{AC}$ was present in 24 -week-old cultures $(\mathrm{p} \leq 0.0001)$. The effect of culture age varied 15 among lines ( $\mathrm{p}=0.003$ for the Lines $\mathrm{x}$ Age interaction): average productivity of the three lines 16 was higher in 8-week-old cultures than in 24-week-old ones ( $\mathrm{p} \leq 0.0001$ for the main effect of 17 age), but the size of this effect varied from a 2.2-fold improvement for line LS8 to a 4.4-fold 18 increase for line LS4.

Quantification of storage proteins

22 The electrophoretic separation of the total protein extracts under non-reducing conditions (Fig. 23 2A) showed the following proteins to be the most abundant: 55.0, 44.8, 37.2, 35.9, 33.3, 21.5, 2416.7 and $14.2 \mathrm{kD}$, whereas under reducing conditions (Fig. 2B) the proteins were: 44.8, 36.3, $2522.0,11.5 \mathrm{kD}$. The $55.0 \mathrm{kD}$ protein complex (a) dissociated into $35.5-36.8$ (a1) and $22-22.4$ 26 (a2) polypeptide sets and represented the buffer-insoluble fraction of $11 \mathrm{~S}$ globulins legumin-like 27 (Bewley and Black 1985, Gifford 1988, Klimaszewska et al. 2004, Brownfield et al. 2007). The $2844.8 \mathrm{kD}$ complex did not dissociate and represented the buffer-soluble fraction of the proteins, 29 7S globulins vicilin-like (Gifford 1988, Klimaszewska et al. 2004, Brownfield et al. 2007). 30 Quantification of the polypeptide sets in cotyledonary stage, mature zygotic embryos as well as 31 in cotyledonary-stage somatic embryos displaying distinct phenotypes showed differences (Table 
1 5). Among the three phenotypes, white somatic embryos had the highest amounts of storage 2 proteins, followed by yellow and green phenotypes. Overall, the somatic embryos of white 3 phenotype accumulated only $4 \%$ less buffer-soluble proteins and $20 \%$ less buffer-insoluble 4 proteins than mature zygotic embryos. Somatic embryos of the green phenotype had $40 \%$ less 5 buffer-soluble proteins and 55\% less buffer- insoluble proteins than zygotic embryos. Somatic embryos of the yellow phenotype had an intermediate level of storage protein accumulation.

7 Germination of green somatic embryos was the most rapid because after one week of culture on 8 the germination medium $92 \%$ of them developed $\sim 0.5 \mathrm{~cm}$ radices followed by $75 \%$ and $56 \%$ of 9 the yellow and white somatic embryos, respectively. However, final germination rates (scored 10 after 6 weeks) for somatic embryos of all phenotypes were over $90 \%$.

12 Plant production (Experiments 3)

14 Experiment 3a: maturation of somatic embryos for plant production from newly initiated lines of 15 crosses A x A and A x B

17 Average somatic embryo production of lines from cross A x B was 4.8 times (C.L.: 2.4, 9.5) as 18 abundant as that of lines from the self cross A x A (averages per cross: 167 (C.L.: 156, 180) and 1935 (C.L.: 18,69$)$ somatic embryos $\mathrm{g}^{-1}$ f.m., respectively; $\mathrm{F}=68.0$ with 1 and 154 d.f.; $\mathrm{p} \leq$ 20 0.0001). Mean somatic embryo production varied among lines within crosses: from 3 (C.L.: 0.3, 21 38) to 233 (C.L.: 168, 324) $\mathrm{g}^{-1}$ f.m. among the four lines from the self-cross, and from 28 (C.L.: $2211,73)$ to 681 (C.L.: 559, 828) $\mathrm{g}^{-1}$ f.m. among those from the out-cross $(\mathrm{F}=21.2$ with 33 and 23154 d.f.; $p \leq 0.0001)$.

25 Experiment $3 \mathrm{~b}$ : germination and conversion of somatic embryos to plants

27 Somatic embryos from lines of the out-cross A x B were more likely to develop into plantlets 28 than those from lines of the self cross A x A ( $F=46.0$ with 1 and 121 d.f.; $p \leq 0.0001)$. The 29 average rate of conversion to plant for the out-cross lines was $62 \%$ (C.L.: $58 \%, 65 \%$ ) and that for 30 the self-cross lines, 28\% (C.L.: 19\%, 39\%). The rate of conversion to plant differed among lines 31 within crosses $(\mathrm{F}=3.74$ with 35 and 121 d.f.; $\mathrm{p} \leq 0.0001)$. Most lines from the self cross had 
1 conversion rates smaller than or equal to $38 \%$ (PS1, PS2, PS3 and PS6), but somatic embryos of

2 line PS4 from the self-cross had a rate of conversion to plant of $62 \%$ (C.L.: $47 \%, 74 \%$ ), equal to

3 the average for the out-cross lines. Somatic embryos from 7 out of 37 lines had rates of

4 conversion to plantlets of $75 \%$ or more. For 34 lines that were common to Experiments $3 a$ and b, 5 the rank correlation between average somatic embryo production and rate of conversion to plant 6 was 0.65 .

8 Experiment 3c: acclimatization in a shade house and plant survival

10 Somatic plants transferred to a potting mix continued to grow under ambient conditions in the 11 shade house. After 4 months, the mean survival rate of plantlets was 73\% (C.L.: 59\%, 83\%) 12 among the four lines of the self-cross, and 81\% (C.L.: 78\%, 84\%) for 31 lines of the A x B out13 cross. The difference was not significant $\left(\chi^{2}=1.68\right.$ with 1 d.f.; $\left.p=0.19\right)$. There was some 14 indication that survival rates varied among lines within crosses $\left(\chi^{2}=54.05\right.$ with 33 d.f.; $p=$ 15 0.01). In March 2006, selected plants were transferred to soil in the nursery where they are 16 currently growing with seedlings. 


\section{Discussion}

3 In this study, tree A was used as the female parent in three of the four crosses including a self cross. SE initiation rates clearly indicated that tree A was the best when used as the female parent with trees $\mathrm{B}$ and $\mathrm{C}$. However, when used as the male parent with tree $\mathrm{C}$ and in selfing, $\mathrm{SE}$ initiation rates were considerably lower. For crosses $\mathrm{C} \times \mathrm{A}$ and $\mathrm{A} \times \mathrm{A}$, they were $5 \%$ and $3 \%$, respectively. The EM of the latter two crosses was difficult to proliferate and survived owing to the special culture technique applied at the onset of the first subculture and afterwards.

The genetic control of SE initiation has already been well documented for various conifer species such as Picea glauca (Park et al. 1993), Pinus sylvestris (Niskanen et al. 2004) and P. 11 taeda (MacKay et al. 2006). In all these studies, the maternal effect was very strong relative to paternal and other effects. The latter report also proposed a strategy to capture large numbers of embryogenic lines per seed family when targeting a small number of full-sib families. The

14 approach was based on evaluating open-pollinated seeds of maternal and paternal trees intended 15 for controlled crosses, and then using seed families from crosses that involved the best SE initiator as maternal parent. Based on our results and those of Häggman et al. (1999), Lelu et al. (1999) and Niskanen et al. (2004), the same approach and breeding strategy would be applicable to Scots pine.

An important result was that the embryogenic lines derived from selfed seeds of tree A 20 proliferated and produced somatic plants. To maintain vigorous growth of the tissue, it was 21 necessary to culture the cells spread on the surface of a filter paper placed on the semi-solid 22 medium. Subsequently, the cultures produced mature somatic embryos and plants, which are 23 presently tested in the nursery. To our knowledge, this is the first demonstration of clonal plant 24 production from a selfed seed family of Scots pine. In the study of Niskanen et al. (2004), two 25 embryogenic lines derived from two selfed seed families proliferated, but no plant regeneration 26 was reported.

27 The explant response of Scots pine to SE initiation indicated that the medium with low concentrations of PGRs was more beneficial than the medium with standard concentrations. 29 Hence, all further experiments were carried out on mLV-L medium, which was also used for 30 proliferation of EM. These results were similar to the responses of Pinus monticola (Percy et al. 312000 ) and $P$. strobus (Klimaszewska et al. 2001), but were opposite to the responses of $P$. 
1 pinaster (Lelu-Walter et al. 2006), which performed better on a medium with standard 2 concentrations of PGRs.

3 ABA concentration had a significant effect on productivity of mature somatic embryos only 4 when tested with $0.2 \mathrm{M}$ sucrose, in which case EM produced 1.4 times more somatic embryos on 5 medium with $80 \mu \mathrm{M}$ ABA than on medium with $120 \mu \mathrm{M} \mathrm{ABA}$. AC was beneficial to older 6 cultures (24-weeks old), but did not seem to affect embryo yield of younger ones (8-weeks old). 7 In a similar study of somatic embryo maturation of $P$. pinaster, charcoal enhanced productivity, 8 irrespective of culture age (Lelu-Walter et al. 2006). It is conceivable that in Scots pine, older 9 embryogenic tissues internalized more PGRs than young ones during the prolonged culture, and 10 that activated charcoal adsorbed some of the PGRs from the cells, reducing their residual effect 11 (Ebert et al. 1993; von Aderkas et al. 2002).

Accumulation level of storage proteins differed among the three phenotypes of cotyledonary 13 somatic embryos. These phenotypes became conspicuous after 10 to 12 weeks of maturation.

14 The green somatic embryos had the lowest contents of buffer-soluble and buffer-insoluble 15 storage proteins compared with those of the white phenotype and zygotic embryos. The green 16 somatic embryos germinated most rapidly after transfer to a germination medium and taken 17 together with the lowest amount of storage proteins indicated that the process might have already 18 started on the maturation medium. White cotyledonary somatic embryos accumulated the highest 19 protein amounts that were close to the amounts in mature zygotic embryos ( $96 \%$ of buffer20 soluble and $80 \%$ of buffer-insoluble storage proteins). These results indicated that there was 21 some asynchrony in the maturation process of somatic embryos and those which matured sooner 22 started germinating while still on the maturation medium. Similar phenomenon was observed in 23 P. strobus somatic embryos where extension of the maturation period resulted in diminished 24 levels of storage proteins caused, most likely, by the onset of germination (Klimaszewska et al. 25 2004). Therefore harvesting time of the somatic embryos must be carefully determined if 26 biochemical similarity with zygotic embryos is required.

27 Production of somatic embryos that have biochemical similarity with zygotic embryos is 28 considered a benchmark of embryo quality and a vigorous post-germinative growth (Pullman et 29 al. 2003). However, this has not been achieved yet in any conifer species. For example, Pinus 30 strobus mature somatic embryos had quantities of storage proteins that were only 50 and $30 \%$ of 31 the buffer-soluble and buffer-insoluble fractions, in their zygotic counterparts, respectively 
1 (Klimaszewska et al. 2004). Similarly lower amounts were also found in mature somatic 2 embryos of interior spruce (Cyr et al. 1991) and white spruce (Misra et al. 1993) indicating the 3 need for further improvements in the maturation treatments for those species. However, recent

$4 \quad$ study in loblolly pine showed that somatic embryos produced less triacylglycerol but more 5 storage protein overall than zygotic embryos (Brownfield et al. 2007). This protein was predominantly buffer-soluble and amounted to a higher ratio of soluble to insoluble proteins compared with zygotic embryos suggesting possible difference in metabolic activity at the time 8 of desiccation.

9 The somatic embryo maturation yield was strongly dependent on the embryogenic line, a 10 phenomenon common to all conifer species. It is noteworthy that there was a correlation between 11 somatic embryo production and rate of conversion to plant. The relatively high, positive rank 12 correlation indicated that lines that produced a lot of somatic embryos were likely to have a 13 higher rate of conversion to plant than lines that produced few somatic embryos. After 4 months 14 of growth in the shade house, average survival rates did not differ between A x A and A x B 15 plants. Six months later, the clonal plants were selected for transfer to a nursery for further 16 growth. Plants were transferred to the field for clonal test in the spring of 2007.

In conclusion, this $P$. sylvestris $\mathrm{SE}$ protocol offers a relatively simple method for accelerated production of large quantities of plants for clonal tests. Based on the above results, we recommend the following:

- Surface disinfection of cones, no disinfection of seed is necessary

- Excision and culture of megagametophytes, with zygotic embryos, at the stage of cleavage polyembryony on mLV-L medium without subculture during the whole initiation period

- Proliferation of the embryonal mass on a filter paper for a rapid increase in tissue fresh mass.

- Simplified cryopreservation method (compared with the published one by Häggman et al. 1998) without the use of programmable freezer.

- Maturation of $200 \mathrm{mg}$ f.m. on a filter paper placed on $\mathrm{mLV}$ medium containing $0.2 \mathrm{M}$ sucrose, $80 \mu \mathrm{M} \mathrm{ABA}$ and $10 \mathrm{gl}^{-1}$ gellan gum for up to 12 weeks, no subcultures are necessary during the entire maturation period 
- Germination of mature somatic embryos on the surface of $\mathrm{mLV}$ medium, in darkness, for the initial 7 to 10 days, followed by exposure to light. Petri dishes should be tilted for the entire period.

9 Acknowledgments Dr C. Bastien of INRA, Orléans is gratefully acknowledged for providing 10 the experimental material and B. Lhomel for performing the cross-pollinations and for cone 11 collections. Part of this work was realized under Canada-France collaboration. 


\section{References}

3 Agresti A (2002) Categorical Data Analysis. $2^{\text {nd }}$ ed., John Wiley \& Sons, New York, 710 p.

4 Bewley JD, Black M (1985) Seeds. Physiology of Development and Germination. Plenum Press, $5 \quad$ New York and London, pp 17-28

Boratynski A (1991) Range of natural distribution. In: Giertrych M, Matyas C (eds) Genetics of Scots Pine, Elsevier, Amsterdam, pp 19-30

8 Brownfield DL, Todd CD, Stone SL, Deyholos MK, Gifford DJ (2007) Patterns of storage protein and triacylglycerol accumulation during loblolly pine somatic embryo maturation. Plant Cell Tiss Org Cult 88:217-223

Cyr D, Webster F, Roberts D (1991) Biochemical events during germination and early growth of somatic embryos and seed of interior spruce (Picea galuca engelmanii complex). Seed Sci Res 1:91-97

14 Ebert A, Taylor F, Blake J (1993) Changes in 6-benzylaminopurine and 2,4-

15 dichlorophenoxyacetic acid concentrations in plant tissue culture media in the presence of 16 activated charcoal. Plant Cell Tiss Org Cult 33:157-162

17 Gifford DJ (1988) An electrophoretic analysis of the seed proteins from Pinus monticola and 18 eight other species of pine. Can J Bot 66:1808-1812

Häggman H, Jokela A, Krajnakova J, Kauppi A, Niemi K, Aronen TS (1999) Somatic embryogenesis of Scots pine: cold treatment and characteristics of explants affecting induction. J Exp Bot 341:1796-1778

Häggman H, Ryynänen LA, Aronen TS, Krajnakova J (1998) Cryopreservation of embryogenic cultures of Scots pine. Plant Cell Tiss Org Cult 54: 45-53

Keinonen-Mettälä K, Jalonen P, Eurola P, von Arnold S, von Weissenberg K (1996) Somatic embryogenesis of Pinus sylvestris. Scand J For Res 11:242-250

Klimaszewska K, Park YS, Overton C, Maceacheron I, Bonga J (2001) Optimized somatic embryogenesis in Pinus strobus L. In Vitro Cell Dev Biol-Plant 37:392-399

Klimaszewska K, Morency F, Jones-Overton C, Cooke J (2004) Accumulation pattern and identification of seed storage proteins in zygotic embryos of Pinus strobus and in somatic 30 embryos from different maturation treatments. Physiol Plant 121:682-690 
1 Lelu MA, Bastien C, Drugeault A, Gouez ML, Klimaszewska K (1999) Somatic embryogenesis

2 and plantlet development in Pinus sylvestris and Pinus pinaster on medium with and without 3 growth regulators. Physiol Plant 105:719-728

4 Lelu-Walter MA, Bernier-Cardou M, Klimaszewska K (2006) Simplified and improved somatic 5 embryogenesis for clonal propagation of Pinus pinaster. Plant Cell Rep 25:767-776

6 Littell RC, Stroup WW, Freund RJ (2002) SAS for linear models. $4^{\text {th }}$ ed., SAS Institute Inc., 7 Cary, NC, $466 \mathrm{p}$.

8 MacKay JJ, Becwar MR, Park Y-S, Corderro JP, Pullman GS (2006) Genetic control of somatic 9 embryogenesis initiation in loblolly pine and implications for breeding. Tree Genetics and 10 Genomes 2:1-9

11 Mize CW, Koehler KJ, Compton ME (1999) Statistical considerations for in vitro research: II 12 data to presentation. In Vitro Cell. Dev. Biol. - Plant 35:122-126

Misra S, Attree SM, Leal I, Fowke LC (1993) Effect of abscisic acid, osmoticum, and desiccation on synthesis of storage protein during the development of white spruce somatic embryos. Ann Bot 71:11-22

Niskanen A-M, Lu J, Seitz S, Keinonen K, von Weissenberg K, Pappinen A (2004) Effect of parent genotype on somatic embryogenesis in Scots pine (Pinus sylvestris). Tree Physiol 24:1259-1265

Park YS, Pond SE, Bonga J (1993) Initiation of somatic embryogenesis in white spruce (Picea glauca): genetic control, culture treatment effects, and implications for tree breeding. Theor Appl Genet 86:427-436

Percy RE Klimaszewska K, Cyr DR (2000) Evaluation of somatic embryogenesis for clonal propagation of western white pine. Can J For Res 30:1867-1876

Pullman GS, Johnson S, Cairney J, Xu N (2003) Improving loblolly pine somatic embryo maturation: comparison of somatic and zygotic embryo morphology, germination, and gene expression. Plant Cell Rep 21:747-758

Quencez C, Bastien C (2000) Genetic variation within and between populations of Pinus sylvestris L. (Scots pine) for susceptibility to Melampsora pinitorqua Rostr. (pine twist rust). Heredity $86: 36-44$

von Aderkas P, Label P, Lelu MA (2002) Charcoal affects early development and hormonal concentrations of somatic embryos of hybrid larch. Tree Physiol 22:431-434 
1 Table 1 Experiment 1a. A) Rates of SE initiation $\left(\mathrm{P}_{\mathrm{I}}, \%\right)$ and rates of EM proliferation $\left(\mathrm{P}_{\mathrm{P}}, \%\right)$ 2 of $P$. sylvestris on $\mathrm{mLV}$ medium with either of two concentrations of PGRs, followed by their 3 95\% confidence limits (Lower, Upper), and B) Analysis including numerator (Num.) and 4 denominator (Den.) degrees of freedom (D.f.), F statistics (F), and their p-values (p)

\begin{tabular}{|c|c|c|c|c|c|c|}
\hline \multicolumn{7}{|l|}{ A) Rates } \\
\hline \multirow{2}{*}{ Medium } & \multirow{2}{*}{$P_{I}$} & \multicolumn{2}{|c|}{$95 \%$ confidence limits } & \multirow{2}{*}{$\mathrm{P}_{\mathrm{P}}$} & \multicolumn{2}{|c|}{$95 \%$ confidence limits } \\
\hline & & Lower & Upper & & Lower & Upper \\
\hline $\mathrm{mLV}-\mathrm{L}$ & 24 & 18 & 30 & 59 & 41 & 75 \\
\hline $\mathrm{mLV}-\mathrm{S}$ & 9 & 06 & 14 & 40 & 18 & 68 \\
\hline
\end{tabular}

B) Analysis

\begin{tabular}{lccccccc}
\hline \multirow{2}{*}{$\begin{array}{l}\text { Source of } \\
\text { variation }\end{array}$} & \multirow{2}{*}{ Num. D.f. } & \multicolumn{3}{c}{ Initiation } & \multicolumn{3}{c}{ Proliferation } \\
\cline { 2 - 8 } & Den. D.f. & $\mathrm{F}$ & $\mathrm{p}$ & Den. D.f. & $\mathrm{F}$ & $\mathrm{p}$ \\
\hline PGR & 1 & 34 & 16.78 & 0.0002 & 28 & 1.39 & 0.25 \\
\hline
\end{tabular}

5

6 
1 Table 2 Experiment 1b: A) Rates of SE initiation $\left(\mathrm{P}_{\mathrm{I}}, \%\right)$ and rates of EM proliferation $\left(\mathrm{P}_{\mathrm{P}}, \%\right)$ on mLV-L medium for seed families

2 of four crosses among $P$. sylvestris trees 818 (A), 785 (B) and 666 (C) followed by their 95\% confidence limits (Lower, Upper), and

3 B) Analysis including numerator (Num.) and denominator (Den.) degrees of freedom (D.f.), F statistics (F), and their p-values (p)

A) Rates

\begin{tabular}{|c|c|c|c|c|c|c|c|}
\hline \multirow{2}{*}{ Mother } & \multirow{2}{*}{ Father } & \multirow{2}{*}{$\mathrm{P}_{\mathrm{I}}$} & \multicolumn{2}{|c|}{$95 \%$ confidence limits } & \multirow{2}{*}{$\mathrm{P}_{\mathrm{P}}$} & \multicolumn{2}{|c|}{$95 \%$ confidence limits } \\
\hline & & & Lower & Upper & & Lower & Upper \\
\hline $\mathrm{C}$ & $\mathrm{A}$ & 5 & 3 & 11 & 50 & 19 & 81 \\
\hline $\mathrm{A}$ & A & 3 & 1 & 8 & 40 & 10 & 81 \\
\hline $\mathrm{A}$ & $\mathrm{B}$ & 25 & 17 & 34 & 93 & 74 & 98 \\
\hline $\mathrm{A}$ & $\mathrm{C}$ & 20 & 14 & 29 & 85 & 65 & 94 \\
\hline
\end{tabular}

B) Analysis

\begin{tabular}{|c|c|c|c|c|c|c|c|}
\hline \multirow{2}{*}{ Source of variation } & \multirow{2}{*}{ Num. D.f. } & \multicolumn{3}{|c|}{ Initiation } & \multicolumn{3}{|c|}{ Proliferation } \\
\hline & & Den. D.f. & $\mathrm{F}$ & $\mathrm{p}$ & Den. D.f. & $\mathrm{F}$ & $\mathrm{p}$ \\
\hline Crosses & 3 & 53 & 13.17 & $\leq 0.0001$ & 28 & 3.53 & 0.03 \\
\hline $\mathrm{AxB}+\mathrm{AxC}$ vs $\mathrm{AxA}^{\mathrm{a}}$ & (1) & $(53)$ & 30.28 & $\leq 0.0001$ & $(28)$ & 5.80 & 0.02 \\
\hline $\mathrm{AxB}$ vs $\mathrm{AxC} \mathrm{C}^{\mathrm{a}}$ & (1) & $(53)$ & 0.54 & 0.47 & $(28)$ & 0.81 & 0.37 \\
\hline $\mathrm{AxA}$ vs $\mathrm{Cx} \mathrm{A}^{\mathrm{a}}$ & (1) & $(53)$ & 0.87 & 0.35 & $(28)$ & 0.12 & 0.73 \\
\hline
\end{tabular}

4 a a priori comparison. 
1 Table 3 Experiment $2 \mathrm{c}$ with $0.2 \mathrm{M}$ sucrose: A) Average number of mature $P$. sylvestris somatic 2 embryos $\mathrm{g}^{-1}$ f.m. followed by their $95 \%$ confidence limits (Lower, Upper), per ABA

3 concentration, per embryogenic line, and B) Analysis including numerator (Num.) and

4 denominator (Den.) degrees of freedom (D.f.), F statistics (F), and their p-values (p)

\begin{tabular}{|c|c|c|c|c|}
\hline \multicolumn{5}{|l|}{ A) Means } \\
\hline \multirow{2}{*}{$\mathrm{ABA}(\mu \mathrm{M})$} & & \multirow{2}{*}{ Mean } & \multicolumn{2}{|c|}{$95 \%$ confidence limits } \\
\hline & & & Lower & Upper \\
\hline 80 & & 248 & 206 & 298 \\
\hline 120 & & 174 & 141 & 214 \\
\hline \multirow{2}{*}{ Cross } & \multirow{2}{*}{ Line } & \multirow{2}{*}{ Mean } & \multicolumn{2}{|c|}{$95 \%$ confidence limits } \\
\hline & & & Lower & Upper \\
\hline$A \times B$ & MS17 & 57 & 33 & 98 \\
\hline$A \times B$ & LS8 & 197 & 157 & 247 \\
\hline$A \times B$ & MS15 & 198 & 144 & 270 \\
\hline$A \times B$ & MS6 & 396 & 358 & 437 \\
\hline$A \times C$ & LS4 & 441 & 383 & 507 \\
\hline
\end{tabular}

B) Analysis

\begin{tabular}{lccccc}
\hline \multicolumn{1}{c}{$\begin{array}{c}\text { Source of } \\
\text { variation }\end{array}$} & \multicolumn{2}{c}{ D. f. } & & F \\
\cline { 2 - 3 } & Num. & Den. & & p \\
\hline ABA & 1 & 98 & 6.26 & 0.014 \\
Lines & 4 & 98 & 34.98 & $\leq 0.0001$ \\
\multicolumn{1}{c}{ Cross $^{\mathrm{a}}$} & $(1)$ & $(98)$ & 75.04 & $\leq 0.0001$ \\
ABA $\times$ Lines & 4 & 98 & 1.57 & 0.19 \\
\hline
\end{tabular}


1 Table 4 Experiment 2d: A) Average number of mature $P$. sylvestris somatic embryos $\mathrm{g}^{-1}$ f.m. embryogenic tissue, ratios of the means 2 per AC level or culture age followed by their $95 \%$ confidence limits (Lower, Upper), per AC concentration and line, per AC

3 concentration and culture age, and per line and culture age, and B) Analysis including numerator (Num.) and denominator (Den.)

4 degrees of freedom (D.f.), F statistics (F), and their p-values (p)

5

A) Means and ratios

\begin{tabular}{|c|c|c|c|c|c|c|c|c|c|c|}
\hline \multirow{3}{*}{ Cross } & \multirow{3}{*}{ Line } & \multicolumn{6}{|c|}{$\mathrm{AC}\left(\mathrm{gl}^{-1}\right)$} & \multirow{3}{*}{ Ratio } & & \\
\hline & & \multirow{2}{*}{10} & \multicolumn{2}{|c|}{$95 \%$ confidence limits } & \multirow{2}{*}{0} & \multicolumn{2}{|c|}{$95 \%$ confidence limits } & & \multicolumn{2}{|c|}{$95 \%$ confidence limits } \\
\hline & & & Lower & Upper & & Lower & Upper & & Lower & Upper \\
\hline $\mathrm{AxC}$ & LS4 & 292 & 246 & 347 & 207 & 163 & 264 & 1.41 & 1.05 & 1.90 \\
\hline $\mathrm{AxB}$ & LS8 & 203 & 170 & 241 & 180 & 146 & 222 & 1.12 & 0.86 & 1.47 \\
\hline $\mathrm{AxB}$ & MS6 & 377 & 330 & 431 & 181 & 145 & 226 & 2.08 & 1.61 & 2.70 \\
\hline \multirow{3}{*}{\multicolumn{2}{|c|}{ Culture age (weeks) }} & \multicolumn{6}{|c|}{$\mathrm{AC}\left(\mathrm{gl}^{-1}\right)$} & \multirow{3}{*}{ Ratio } & \multirow{2}{*}{\multicolumn{2}{|c|}{$95 \%$ confidence limits }} \\
\hline & & \multicolumn{4}{|c|}{$95 \%$ confidence limits } & \multicolumn{2}{|c|}{$95 \%$ confidence limits } & & & \\
\hline & & 10 & Lower & Upper & 0 & Lower & Upper & & Lower & Upper \\
\hline 8 & & 406 & 375 & 440 & 384 & 353 & 418 & 1.06 & 0.94 & 1.19 \\
\hline 24 & & 196 & 165 & 231 & 93 & 73 & 119 & 2.10 & 1.56 & 2.83 \\
\hline
\end{tabular}

Culture age (weeks)

\begin{tabular}{|c|c|c|c|c|c|c|c|c|c|c|}
\hline \multirow{2}{*}{ Cross } & \multirow{2}{*}{ Line } & \multirow{2}{*}{8} & \multicolumn{2}{|c|}{$95 \%$ confidence limits } & \multirow{2}{*}{24} & \multicolumn{2}{|c|}{$95 \%$ confidence limits } & \multirow{2}{*}{ Ratio } & \multicolumn{2}{|c|}{$95 \%$ confidence limits } \\
\hline & & & Lower & Upper & & Lower & Upper & & Lower & Upper \\
\hline $\mathrm{AxC}$ & LS4 & 516 & 474 & 563 & 117 & 88 & 156 & 4.40 & 3.27 & 5.93 \\
\hline $\mathrm{AxB}$ & LS8 & 285 & 254 & 320 & 128 & 100 & 164 & 2.23 & 1.70 & 2.92 \\
\hline
\end{tabular}




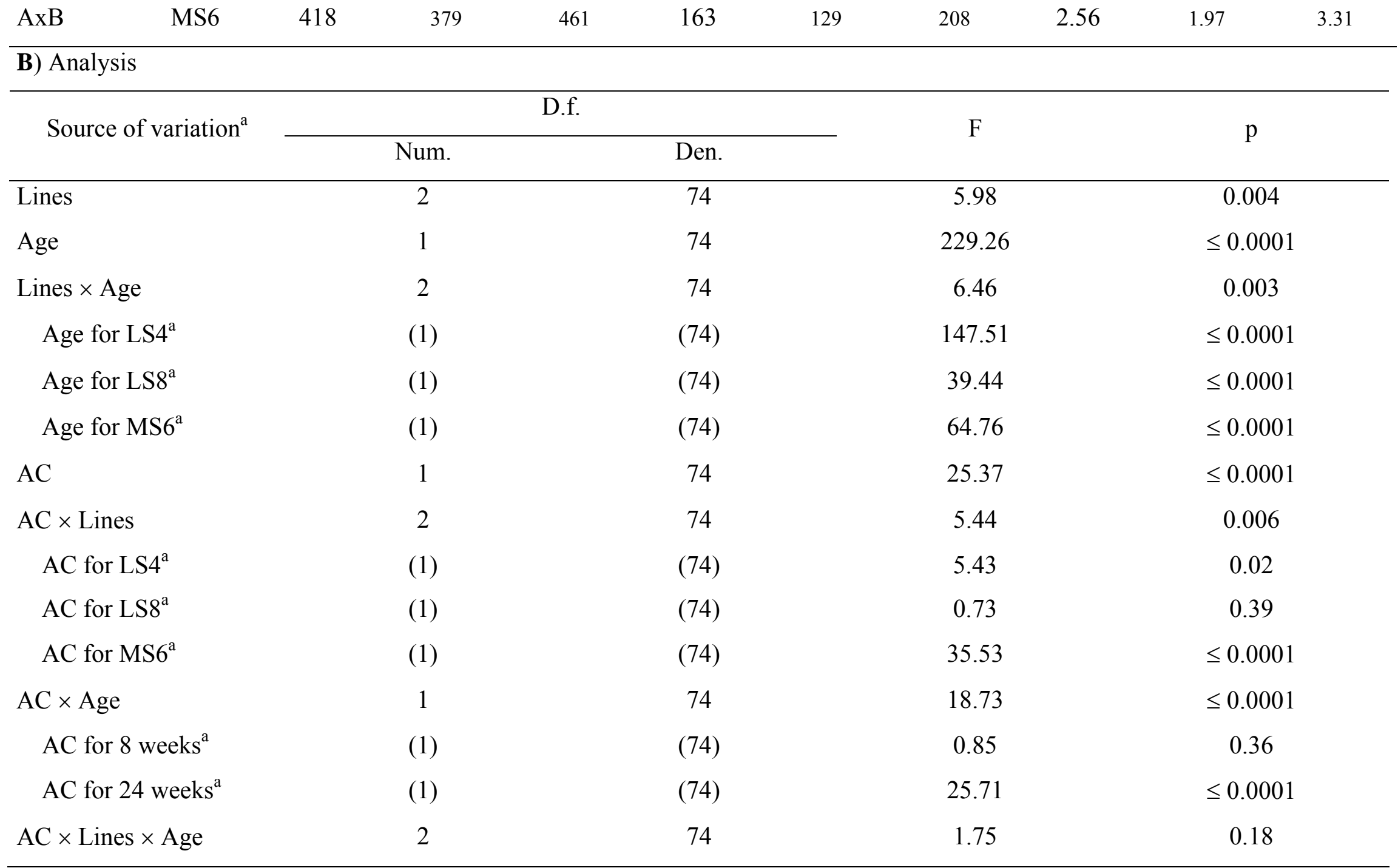

1 a priori comparisons. 


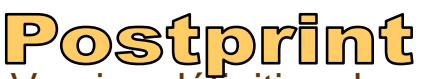

Version détinitive du manuscrit publié dans / Final version of the manuscript published in : Plant Cell Tissue and Organ Culture. 2008, 92 (1) : 31-45

1 Table 5 Relative quantities of major storage protein sets in P. sylvestris mature somatic

2 embryos of the white, yellow and green phenotypes in comparison with those of mature zygotic

3 embryos, which were set to $100 \%$.

\begin{tabular}{ccccc}
\hline \multirow{2}{*}{ Phenotype } & \multicolumn{4}{c}{ Storage protein sets } \\
\cline { 2 - 5 } & $45 \mathrm{kD}$ & $36 \mathrm{kD}$ & $22 \mathrm{kD}$ & $11.5 \mathrm{kD}$ \\
\hline \multirow{2}{*}{ White } & 96 & 78 & 78 & 74 \\
Yellow & 53 & 48 & 54 & 48 \\
Green & 63 & 34 & 48 & 47 \\
\hline
\end{tabular}

4 


\section{Figure legends}

2

3 Fig. 1 Clonal somatic seedling production from somatic embryos of $P$. sylvestris (A) Examples

4 of mature somatic embryos selected for germination. Note varying numbers (3 to 7) of cotyledon

5 primordia. (B) Germinated somatic embryo. (C) Elongated somatic seedlings at the later stages

6 of growth compared with (B). Insert shows formation of secondary root primordia on a primary

7 root. (D) Clonal somatic seedlings grown in a shade house for 9 months. Bar $=1 \mathrm{~mm}$ (A), $1 \mathrm{~mm}$

8 (B), $1 \mathrm{~cm}(\mathrm{C}), 3 \mathrm{~cm}(\mathrm{D})$.

10 Fig. 2 Coomasie blue-stained SDS-PAGE profiles of total proteins of $P$. sylvestris zygotic 11 embryos (z) and somatic embryos of white (sw), yellow (sy) and green (sg) phenotypes under 12 (A) non-reducing conditions and (B) reducing conditions. Molecular mass indicators in $\mathrm{kD}$ are 13 shown on the left side. Arrows and letters indicate storage proteins. Each lane received $15 \mu \mathrm{g}$ 14 proteins in $15 \mu 1$.

15 